\title{
Logística e troca eletrônica de informação em empresas automobilísticas e alimentícias
}

\author{
Karine Araújo Ferreira \\ Maria Rita Pontes Assumpção Alves \\ Universidade Federal de São Carlos
}

\section{Resumo}

Este artigo analisa impactos na logística pela troca eletrônica de informações entre empresas (com uso de EDI Electronic Data Interchange e Internet), destacando a diferença destes impactos em empresas das indústrias alimentícia e automobilística. As empresas são pressionadas por parceiros para adoção destas tecnologias: a montadora é a responsável na cadeia automobilística e o grande varejo é o disseminador na cadeia alimentícia. $\mathrm{O}$ EDI pressupõe relações contratuais entre as empresas. As processadoras de alimentos observaram redução de erros e no tempo dos ciclos de pedido, assim como melhoria na visibilidade dos estoques e no planejamento de transporte para distribuição de seus produtos. Já nas empresas da indústria automobilística, os impactos são mais significativos no tempo e custo de processamento de pedido, com redução nos níveis e custo de estoque e de transporte para suprimento. Os resultados são de pesquisa de natureza qualitativa - estudos de casos.

\section{Palavras-chave}

Logística, tecnologia de informação, indústria de alimentos, indústria automobilística.

\section{Logistics and electronic information interchange in automotive and food companies}

\begin{abstract}
This paper analyzes the impacts of electronic information exchange (EDI - Electronic Data Interchange and Internet) toward companies' logistics performance, emphasizing the difference of these impacts within food and automobile industries. Companies are being impelled by their partners to adopt these information technologies, whether: vehicle assemblers are responsible for the automobile chain; and great retailers work as disseminators through the food chain. EDl's implementation requires contractual relations among companies. Therefore, food processing industries aim to reduce both errors and cycle-time orders; as well as to improve inventory visibility and transport planning in the distribution of its products. However, in the automobile companies segment, the impacts are more significant in time and order processing costs, with the reduction of inventory and transport level's costs for supplying. The presented results are of qualitative research nature - case studies.
\end{abstract}

Key words

Logistics, information technology (IT), food industry, automotive industry. 


\section{INTRODUĈ̣̃O}

A gestão de operações na economia globalizada tem induzido as organizações a promoverem uma reestruturação produtiva que pode ser verificada pelas mudanças tecnológicas, organizacionais e comerciais de suas atividades. Um dos aspectos mais presentes nas decisões empresariais é o de externalizar tarefas, antes da responsabilidade direta da organização. Este aspecto implica na gestão do fluxo produtivo e comercial permeado em rede de organizações, onde a gestão da cadeia de suprimento tem se tornado conceito-chave para entender e saber aplicar, e a logística, uma função importante para gerenciar adequadamente. O uso das informações, facilitado pelo avanço da tecnologia de informação e comunicação (TIC), passa a ter papel fundamental nas organizações, possibilitando melhor percepção das mudanças, maior flexibilidade e agilidade nas operações.

Dentre as tecnologias com aplicação na logística, procurou-se analisar neste trabalho duas tecnologias utilizadas na troca eletrônica de informações entre empresas: EDI (Electronic Data Interchange, ou troca eletrônica de dados) e Internet. Diversos autores têm destacado os impactos do EDI e da Internet na gestão logística, indicando os principais: redução nos níveis de estoques e de fretes adicionais nas entregas, diminuição de erros, agilidade na transmissão e processamento de pedidos, entre outros. (BOWERSOX \& CLOSS, 2001; LANCIONI et al., 2003; STANK et al., 1999).

O objetivo deste trabalho é analisar o impacto do uso da troca de informações entre parceiros comerciais nas atividades logísticas de empresas das indústrias automobilística e de alimentos. As atividades a serem avaliadas sob o impacto da troca eletrônica de informações e foco deste trabalho são: gestão de estoques (como se processa e apóia as operações no fluxo físico), transporte e processamento de pedidos. Este escopo de análise é definido por considerá-las como as principais atividades de interface da empresa com seus parceiros de negócios e mais sujeitas a sofrerem impactos, caso a troca de informação não ocorra de forma ágil e precisa. A pesquisa realizada neste trabalho é de natureza qualitativa, e nela foi elaborada uma comparação entre os resultados obtidos através de estudos de caso exploratórios realizados em empresas da indústria automobilística (FERREIRA, 2003; GALLINA, 2001; ANTONIO, 2003) e da indústria de alimentos (FERREIRA et al., 2004).

Primeiramente é apresentado o conceito de sistema logístico e suas principais atividades, seguido pelos conceitos de EDI e Internet. Os principais impactos da troca eletrônica de informações nas atividade-chave da logística são discutidos posteriormente e, continuando, os estudos de caso relatando a aplicação destas tecnologias e seus principais impactos em empresas dos setores automobilístico e de alimentos, assim como análise comparativa do uso destas TIs nestes dois setores. Por fim, são apresentadas as considerações finais do trabalho, seguidos pelas referências bibliográficas.

\section{O SISTEMA LOGÍSTICO}

A palavra logística é de origem francesa - do verbo loger, que significa "alojar", estando associada ao suprimento, deslocamento e acantonamento de tropas, tendo, portanto, sua origem ligada às operações militares. Embora a logística tenha sido presente em toda a atividade produtiva ao longo da história, sua importância ganha destaque e tem evolução continuada com a globalização, sendo desenvolvida primeiramente na década de 1980 nos países desenvolvidos e, na década de 1990, nos países em desenvolvimento, com a desregulamentação das economias nacionais. Atualmente, é considerada um dos elementos fundamentais na estratégia competitiva das empresas.

\section{$\Lambda$ administração eficiente do fluxo de bens para atender à demanda exige planejamento, programação e controle das atividades logísticas.}

\footnotetext{
O Council of Supply Chain Management Professionals define logística como "parte da Gestão da Cadeia de Suprimentos que planeja, implementa e controla de maneira eficiente e efetiva o fluxo direto e reverso e a armazenagem de produtos, bem como os serviços e informações associados, cobrindo desde o ponto de origem até o ponto de consumo, com o objetivo de atender aos requisitos do consumidor" (COUNCIL OF SUPPLY CHAIN MANAGEMENT PROFESSIONALS, 2005).

A aplicação da logística como recurso competitivo baseia-se na sua gestão de forma integrada, sendo tratada como um sistema, ou seja, um conjunto de componentes interligados, atuando de forma coordenada em busca de objetivo comum. Este sistema é composto pelos canais logísticos que se estendem a jusante (distribuição para o mercado consumidor) e a montante (fornecimento de peças e componentes) da empresa. A gestão da logística integrada cuida da movimentação dos produtos entre três
} 
áreas: suprimento, apoio à produção e distribuição física, vinculando a empresa a seus clientes e fornecedores (Figura 1).

A área sombreada na Figura 1 representa a necessidade de integrar as operações de compra, produção e marketing (vendas) da empresa, que, por outro lado, devem ser integradas com as operações dos fornecedores e clientes. De acordo com Bowersox \& Closs (2001), as informações recebidas de clientes e sobre eles fluem pela empresa na forma de atividades de vendas, previsões e pedidos. Estas são filtradas em planos específicos de compras e de produção. No momento do suprimento de produtos e materiais, é iniciado um fluxo de bens de valor agregado que resulta na transferência de propriedade de produtos acabados aos clientes. Neste processo, verificam-se duas ações inter-relacionadas, fluxo de materiais e fluxo de informações, que devem ser coordenadas, dado que o fluxo de informações segue caminhos paralelos ao fluxo de materiais.

A administração eficiente do fluxo de bens para atender à demanda exige planejamento, programação e controle do sistema logístico. A gestão das atividades deste sistema varia de empresa para empresa, dependendo da sua estrutura organizacional e da importância destas atividades para suas operações.

Este trabalho limita sua análise ao uso da troca de informações entre parceiros comerciais imediatos que afetam as atividades logísticas, selecionando três atividades consideradas essenciais sob a ótica dos diversos autores investigados: transporte, gestão de estoques e processamento de pedidos. A questão de pesquisa que norteia esta análise é: "Como a troca eletrônica de informação suporta a coordenação das operações de transporte, gestão de estoques e processamento de pedidos"?
Neste item são discutidos os principais aspectos destas três atividades.

\section{Gestão de Estoques}

Os estoques representam o maior investimento individual em ativos para a maioria dos fabricantes, atacadistas e varejistas. $\mathrm{O}$ investimento em estoques pode representar mais de $20 \%$ dos ativos de um fabricante e mais de $50 \%$ dos ativos totais de atacadistas e varejistas (LAMBERT et al., 1998). No entanto, eles são importantes para gestão logística, para equilíbrio entre oferta e demanda, assegurando disponibilidade de produtos necessários aos clientes industriais, dos canais de distribuição e finais.

A gestão de estoques trata dois tipos de decisões na cadeia de suprimento: estratégicas e táticas. As decisões estratégicas sobre estoques na cadeia de suprimento envolvem questões sobre onde o estoque deve ser situado e qual abordagem (empurrado e centralizado ou puxado e descentralizado) deve ser adotada para seu controle. As decisões táticas tratam de políticas de controle de estoque em que a otimização dos níveis de estoque é para toda a cadeia de suprimentos, ao invés de buscar o ótimo em cada um dos seus estágios/pontos de armazenagem (GIANNOCCARO \& PONTRANDOLFO, 2000).

As decisões táticas e estratégicas são influenciadas pelas estratégias e a estrutura da cadeia de suprimentos, assim como pelos aspectos organizacionais para seu funcionamento. A estratégia reflete as metas dos negócios das empresas e suas estratégias de produção (fazer para estoque - MTS, fazer sob pedido MTO, etc.) para atingilas. A estrutura é relacionada a dimensões físicas e geográficas da cadeia de suprimentos, identificando a posição do ponto de desacoplamento (decoupling point), ou seja, o ponto na cadeia de suprimentos onde o produto

Figura 1: Logística integrada.

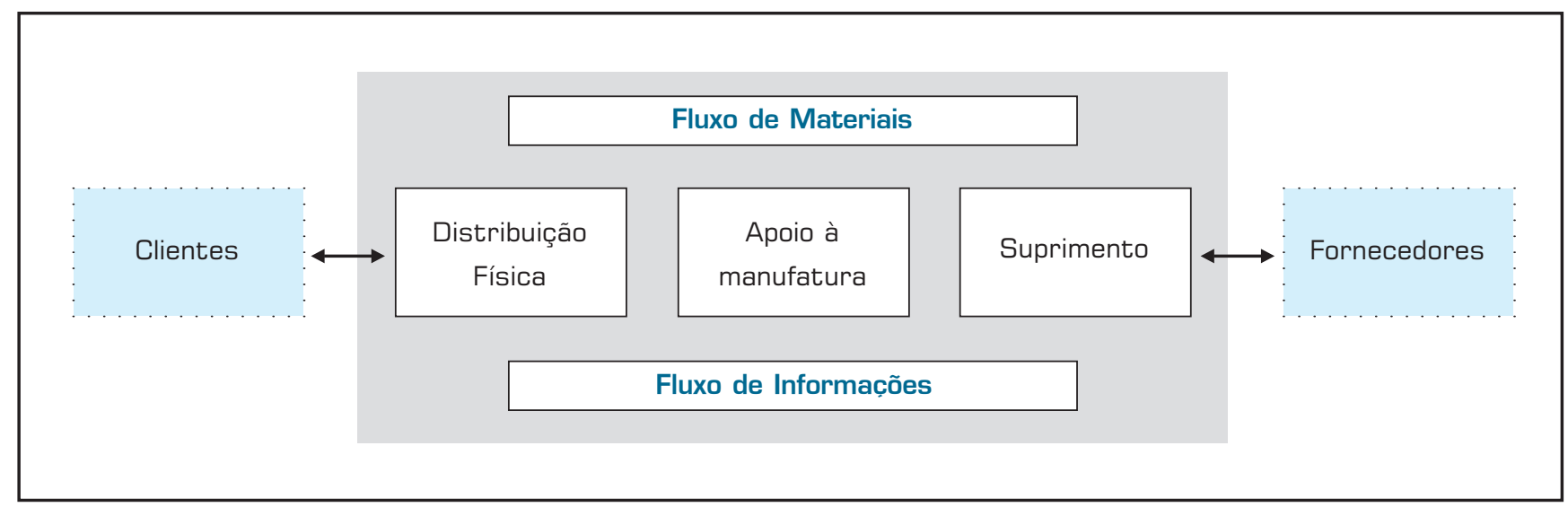

Fonte: Bowersox \& Closs (2001, p. 44) 
deixa de ser produzido para estoque e passa a ser produzido para atender a um pedido explicitado (HOEK et al., 1999). Os aspectos organizacionais referem-se aos relacionamentos interorganizacionais. São fatores importantes para análise do relacionamento entre as empresas: o poder de barganha das mesmas (explicitado nos contratos e/ou em acordos comerciais), o grau de complexidade das interações entre as empresas (número de áreas funcionais que compartilham solução de problemas) e o grau de integração vertical (HAGELAAR et al., 2002).

De acordo com Wanke (2000), uma política de estoques define: (1) quanto pedir, (2) quando pedir, (3) quanto manter em estoques de segurança, (4) onde localizar. Slack (2002) acrescenta ainda a definição de quais procedimentos e rotinas devem ser adotados para apoio a estas decisões. Para definição da política de estoques, são avaliados os custos de: colocação de pedidos, falta de estoque, armazenagem, ineficiência de produção, giro de estoque e descontos de preço por quantidade pedida para decidir quanto comprar.

A definição de quanto pedir baseia-se em abordagens para determinação de lote econômico de compra, lote econômico de produção e ponto de ressuprimento, enquanto técnicas de revisão contínua ou periódica auxiliam a decisão de quando pedir. Para o controle e gestão de estoques, Lambert et al. (1998) destacam: a análise da curva ABC, o uso de técnicas de previsão de demanda e sistemas para adiantamento no processamento de pedidos. Métodos de controle de estoque como programação just-in-time (JIT), Kanban, sistema de planejamento de necessidades de materiais (MRP), auxiliam na garantia da disponibilidade de produtos. Wanke (2000) indica quais fatores devem ser observados na localização de estoques e determinação de maior ou menor grau de centralização para controle dos estoques: características do produto, comportamento da demanda, nível de exigência do mercado, grau de flexibilidade do processo de fabricação, acesso à informação em tempo real e existência de economias de escala no transporte.

Vale ressaltar, enfim, que práticas de planejamento e gestão colaborativa na cadeia de suprimentos vêm sendo cada vez mais usadas pelas empresas para gestão eficiente dos estoques. Entre iniciativas de planejamento e gestão colaborativa na cadeia de suprimentos, Pires (2004) destaca: ECR (Efficient Consumer Response-resposta eficiente ao consumidor), VMI (Vendor Management Inventory - estoque gerenciado pelo fornecedor), CR (Continuous Replenishment - reposição contínua) e CPFR (Collaborative Planning, Forecasting, and Replenishment - planejamento, previsão e reposição/reabastecimento colaborativo), todos apoiados por troca eletrônica de informações.

\section{Transporte}

O transporte para movimentação de matérias-primas e/ou produtos acabados representa a maior parcela dos custos logísticos na maioria das empresas. Nazário (2000) afirma que o transporte representa, em média, $60 \%$ das despesas logísticas da empresa, significando de $4 \%$ e $25 \%$ do seu faturamento bruto, dependendo do seu ramo de atuação. $\mathrm{O}$ avanço da tecnologia de equipamentos de transporte e iniciativas como a intermodalidade (integração de vários modais de transporte) e a terceirização desta atividade a operadores logísticos (prestadores de serviços logísticos) têm sido importantes para a redução dos custos de transporte. 
transportadores, equilíbrio ou desequilíbrio do tráfego de fretes em um território, sazonalidade das movimentações de produtos e se o produto está sendo transportado dentro do país ou internacionalmente. Reduzir o custo dos transportes e também melhorar o serviço ao cliente são objetivos esperados do serviço logístico.

No Brasil, uma das principais barreiras para o desenvolvimento da logística está relacionada com as enormes deficiências encontradas na infra-estrutura de transportes e comunicação. Dados publicados na revista As Maiores do Transporte mostram que o transporte brasileiro apresenta uma exagerada dependência do modal rodoviário, o segundo mais caro, atrás apenas do aéreo. Com a expressiva participação de $65 \%$ a $75 \%$ na matriz dos transportes brasileiros, seguido por cerca de $20 \%$ da ferrovia, o transporte rodoviário é o grande eixo de movimentação de cargas no transporte brasileiro (A MELHOR, 2001).

\section{Fluxo de Informação e Processamento de Pedidos}

O uso de tecnologias de informação e telecomunicação (TI) impacta a eficiência do sistema logístico, agilizando seu fluxo de informação e oferecendo capacidade de resposta ao seu fluxo físico. O fluxo físico representa a movimentação e armazenagem de produtos, desde matériasprimas, insumos ou materiais componentes até produtos acabados, desde o fornecedor até o consumidor final. Este fluxo vai na direção do mercado final e, ocasionalmente, tem sua direção invertida (logística reversa). O fluxo de informações, segundo Bowersox \& Closs (2001), dá apoio ao planejamento e execução das operações logísticas de maneira integrada, por meio da coordenação de planos de capacidade, necessidades e programação (fluxo de coordenação) e de controle das operações para atendimento à demanda (fluxo operacional) (Figura 2).

A coordenação objetiva a integração de planos que especificam: objetivos estratégicos, restrições de capacidade, necessidades logísticas, posicionamento de estoque, necessidades de fabricação e necessidades de suprimento. Já a programação e controle das operações são referentes a: gestão de pedidos, processamento de pedidos, operações de distribuição, gestão de estoque, transporte e expedição e suprimento. Estes dois níveis de informação - coordenação e programação e controle -, são conectados pela previsão da demanda e sofrem retroalimentação sobre os níveis de estoque para tomada de decisão. É o processamento de pedidos quem dispara os processos logísticos e atividades necessárias para entregar produtos para os consumidores. Assim, pode-se entender o papel das informações no desempenho de atividades logísticas analisando-se o sistema de processamento de pedidos e o ciclo do pedido.

\section{Processamento de Pedidos}

O ciclo do pedido vai desde a colocação do pedido pelo comprador até o recebimento pelo solicitante, consistindo das seguintes etapas: criação do pedido, geração da fatura, emissão de documentos para separação da mercadoria e verificação de pedidos, verificação da reserva de estoque, processamento do pedido, atendimento

Figura 2: Necessidades de Informações Logísticas.

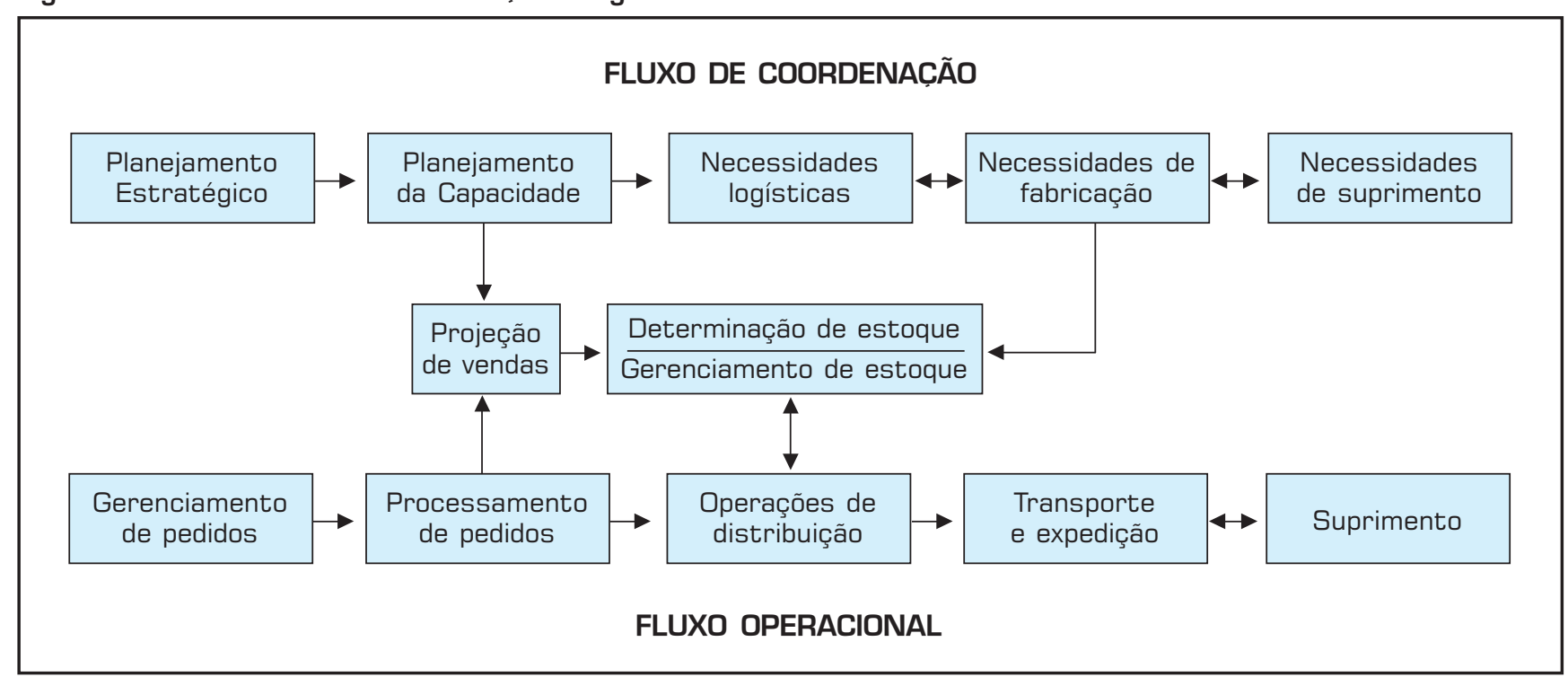

Fonte: Bowersox \& Closs (2001, p.47). 
do pedido, liberação de estoque reservado, liberação do pedido totalizado e verificação da expedição para entrega e transporte (BOWERSOX \& CLOSS, 2001).

As atividades de processamento de pedidos podem representar, conforme os meios para fazê-lo, a maior parte do tempo total do ciclo do pedido. Preparação, entrada e preenchimento do pedido podem representar $50 \%$ a $70 \%$ do tempo total do ciclo de pedido em muitas empresas (BALLOU, 2001). Com uso das TICs, estes elementos têm sido agilizados pelo uso de código de barras, captação eletrônica de dados, processamento computadorizado dos pedidos e comunicação eletrônica. A adoção de sistema eficiente de processamento de pedidos aumenta a produtividade dos ativos empregados no ciclo de pedidos, permitindo melhoria significativa do serviço ao cliente, com redução de custos pela eliminação de erros e redundâncias e rapidez no fluxo de caixa (LAMBERT et al., 1998).

Para Ballou (2001), a seleção do hardware e de sistemas para processamento do pedido representa apenas parte das considerações do projeto logístico. Fatores como procedimentos operacionais, políticas de serviço ao cliente e práticas de transporte estão entre os diversos fatores que podem alterar o tempo do ciclo do pedido. Conforme Lambert et al. (1998), as decisões relacionadas ao processamento de pedidos podem ser agrupadas em decisões estratégicas e operacionais. No nível estratégico, as decisões principais são: automatização e se os pedidos devem ser feitos de forma centralizada ou descentralizada. Já questões operacionais englobam localização do pedido, validação do pedido, checagem de crédito do cliente, reconciliação de faturas e composição do pedido.

\section{TECNOLOGIAS DE INFORMAC̄ÃO E TELECOMUNICAC̣ÃO: EDI E INTERNET}

Segundo Lankford \& Johnson (2000), o EDI, abreviação de Electronic Data Interchange, ou, em português, Intercâmbio Eletrônico de Dados, é uma forma de comunicação eletrônica que permite a troca de informações e documentos em formatos estruturados que podem ser processados por determinado tipo de software. O EDI recebe diferentes classificações, de acordo com o meio usado para intercâmbio de informações (EAN BRASIL, 2003). O uso de redes proprietárias, pelas quais as empresas acessam sua caixa postal para envio e recepção de documentos, constitui o EDI via VAN, também conhecido como EDI Tradicional. VAN (Value Added Network) é a denominação mais usual para as referidas redes pro- prietárias. Quando as empresas usam o EDI via Internet para o tráfego de documentos diz-se que a troca eletrônica é Web EDI, quando é utilizado um browser (aplicativo para visualização das páginas na Internet) e um serviço especial de conexão na Internet, disponibilizado pelas operadoras do serviço de telecomunicação. Este meio expandiu o uso de EDI para aqueles que processam um baixo volume de documentos de negócio, por representarem menores investimentos na aquisição de hardware dedicado e proprietário.

\section{mbora a Internet apresente custo de} implementação bem mais baixo que o ela é mais vulnerável e menos segura.

A Internet é definida como a maior rede de computadores do mundo, que integra redes locais, regionais e nacionais (LAUDON \& LAUDON, 1999).

A escolha para uso do EDI (tradicional ou via Web) ou Internet deve considerar custo do investimento e de operação, número de parceiros para troca eletrônica e requisitos de segurança. Embora a Internet apresente custo de implementação bem mais baixo que o EDI, ela é mais vulnerável e menos segura. Por outro lado, enquanto o EDI exige um relacionamento prévio entre parceiros que pretendem utilizar esta tecnologia de informação para troca de informação, a Internet pode ser utilizada mais facilmente por maior amplitude de parceiros, sem a necessidade de relacionamento prévio entre os mesmos. Seu uso tem sido ampliado com a garantia de maior segurança para envio de documentos via Internet.

\section{O IMPACTO DO USO DA TROCA ELETRÔNICA DE INFORMAC̣̃̃O NA GESTÃO DAS ATIVIDADES LOGÍSTICAS}

Quando as tecnologias EDI e Internet são utilizadas de forma adequada, há oportunidades de melhoria de desempenho nas operações logísticas. Segundo Lambert et al. (1998), estas tecnologias impactam vários aspectos da empresa, com destaque para a logística, principalmente em transporte, armazenagem, processamento de pedidos, gestão de estoques, afetando significativamente as áreas de suprimentos /compras e distribuição.

A capacidade de maior visibilidade no fluxo logístico permite redução nos níveis de estoque, sem comprometer o atendimento à demanda. $\mathrm{O}$ uso de EDI permite às empresas melhorar sua gestão e controle da produção, permitindo 
reposição contínua conforme as necessidades (EAN BRASIL, 2003). O uso da Internet permite redução de estoque nos canais de suprimento e de distribuição física, evitando obsolescência de produtos (HASSELBRING \& WEIGAND, 2001; LAMBERT et al., 1998; BALLOU, 2001; BOWERSOX, 2001; MACHUCA \& BARAJAS, 2003).

O uso de EDI e Internet na logística de transportes está na transmissão das informações e documentação, na possibilidade de rastreamento da carga, no controle dos processos de carga e descarga. Alguns benefícios apontados na literatura são: redução de custos por evitar fretes adicionais, do gasto em paradas de veículo (pelo aguardo de transação de documentos, como nota fiscal), do tempo de atendimento, solidificação no relacionamento entre cliente e transportadora, melhoria das condições para planejamento das operações logísticas, facilitando o processo de licitação de serviços de transporte (GALLINA, 2001; FERREIRA, 2003; ATKINSON Apud LANCIONI et al., 2003).

O processamento de pedidos é a atividade que a empresa mais faz com uso da Internet, crescendo de 52,1\% em 1999 para 55,5\% em 2001 (LANCIONI et al., 2003). Esta atividade pode ter apoio com troca de mensagens eletrônicas, não apenas de documentos. Os benefícios da automação do processamento de pedidos, além de melhoria do serviço ao cliente são: melhor disponibilidade de produto e acesso a informações sobre pedidos pendentes, exatidão das faturas, menores níveis de estoque de segurança e seus custos correspondentes (LAMBERT et al., 1998). O EDI é capaz de reduzir o tempo de processamento de pedidos (ciclo de pedidos) e conseqüentemente o custo de processamento de pedidos, aumentar a produtividade dos funcionários nesta tarefa, liberando-os para realização de atividades mais importantes, como por exemplo a negociação com os fornecedores (GALLINA, 2001; CHOPRA \& MEINDL; 2003).

O Quadro 1 sintetiza as influências do uso de EDI e Internet nas atividades logísticas: gestão de estoques, transporte e processamento de pedidos, apontadas na literatura.

\section{ESTUDOS DE CASO}

A seguir são apresentados estudos que relatam o uso e os impactos de tecnologias para troca eletrônica de informações nas atividades logísticas de empresas da indústria automobilística, no canal de fornecimento e na distribuição (FERREIRA, 2003; GALLINA, 2001; ANTONIO, 2003), e na indústria de alimentos, em quatro empresas do segmento de balas e doces, chocolates, biscoitos e bebidas e em uma usina de açúcar (FERREIRA et al., 2004). O Quadro 2 apresenta características gerais das empresas.

\section{Troca eletrônica de informações em empresas da indústria automobilística}

O uso da troca eletrônica de informações já é bem disseminado entre empresas do ramo automobilístico, cuja adoção nas empresas pesquisadas ocorreu há mais tempo que nas empresas de alimentos, devido à exigência das montadoras para se comunicarem com seus fornecedores.

Em uma empresa fornecedora de autopeças para empresas automobilísticas, verificou-se que o EDI é usado no recebimento da necessidade de produção enviada pelos clientes imediatos e para o envio de pedidos de compras aos seus fornecedores. A mensagem enviada

Quadro 1: Possiveis influências do EDI e da Internet nas atividades logísticas.

\begin{tabular}{|l|l|}
\hline \multicolumn{1}{|c|}{ ATIVIDADE } & \multicolumn{1}{|c|}{ INFLUÊNCIAS DA COMUNICAÇÃO ELETRÔNICA VIA EDI E INTERNET } \\
\hline $\begin{array}{l}\text { Gestão de } \\
\text { Estoques }\end{array}$ & $\begin{array}{l}\text { - a informação com menos erros e em tempo real pode resultar na redução dos níveis de estoques, } \\
\text { evitando, assim, custos desnecessários, perda de capital de giro e obsolescência de produtos; } \\
\text { - a diminuição de incertezas e a melhor percepção da demanda proporcionadas pela troca } \\
\text { eletrônica de informações permitem maior visibilidade para planejamento e controle de estoques. }\end{array}$ \\
\hline Transporte & $\begin{array}{l}\text { - pode possibilitar melhor planejamento de entrega de produtos, eliminando a necessidade de } \\
\text { fretes adicionais e reduzindo custos; } \\
\text { - pode eliminar o tempo em que os veículos ficam parados, esperando a realização de transações }\end{array}$ \\
\hline $\begin{array}{l}\text { Processamerciais, como emissão de notas fiscais; } \\
\text { de Pedidos }\end{array}$ & $\begin{array}{l}\text { - a eliminação de processos manuais de revisão e digitação e a padronização de informações } \\
\text { podem permitir agilidade na transmissão, recebimento, processamento de pedidos e redução de } \\
\text { erros;- pode reduzir o tempo de processamento dos pedidos, tempo de ciclo dos pedidos e } \\
\text { conseqüentemente, o custo de processamento de pedidos. }\end{array}$ \\
\hline
\end{tabular}

Fonte: Elaborado pelas autoras a partir de Bowersox \& Closs (2001), Ballou (2001), Chopra \& Meindl (2003), Lancioni et al.(2003). 
pelos clientes é recebida pela área de logística, que é responsável pelo tratamento e análise das informações recebidas. Depois da verificação e tratamento dos dados, é feito o cálculo das necessidades de materiais e recursos de produção, que é enviado, respectivamente, aos setores de compra e produção. A área de expedição utiliza o EDI para a emissão de aviso de embarque e notas fiscais aos fornecedores e operadores logísticos.

A logística é uma das principais áreas afetadas pelo uso do EDI nesta empresa. Na gestão de estoques, a informação em tempo real permite o planejamento e controle de seus estoques com maior eficiência, possibilitando a redução nos seus níveis, evitando assim custos desnecessários, perda de capital de giro e obsolescência dos produtos. Na programação de entrega e transportes, o uso do EDI possibilitou melhorar a atividade de planejamento de entrega de produtos, eliminando a necessidade de fretes adicionais. Elimina o tempo que os veículos ficam parados, esperando para a realização de transações comerciais, como a emissão de notas fiscais. No processamento de pedidos, verificou-se principalmente agilidade na transmissão e processamento de pedidos, bem como redução de erros de digitação.

Resultados semelhantes foram encontrados em pesquisas realizadas no ano de 2001 em outras três empresas fornecedoras de componentes da indústria automobilística, denominadas Tier 1 ou 1 o nível (empresa sistemista e fornecedora de retrovisores para as montadoras), empresa Tier 2 ou 2ํㅡ́ㄹel (empresa subsistemista e fornecedora de cabos flexíveis e peças plásticas) e Tier 3 (empresa fornecedora de componentes plásticos para as empresas Tier 1 e Tier 2).
A informação em tempo real permitiu uma redução nos níveis de estoque e conseqüente redução dos custos de estoque de $\mathrm{R} \$ 6.750,00$ (empresa Tier 1), $\mathrm{R} \$ 500,00$ (Tier 2) e R \$900,00 (Tier 3), respectivamente. Na gestão de transportes foram verificados também redução de custos de fretes adicionais nas três empresas pesquisadas, sendo a mais significativa na empresa Tier 1 (R\$ 72.000,00). O uso do EDI proporcionou também redução em horas gastas com digitação e redução no tempo de processamento do pedido, o que resultou na economia com custos de processamento de pedidos de $\mathrm{R} \$ 26.208,00$ (Tier 1), $\mathrm{R} \$ 3.952,00$ (Tier 2) e $\mathrm{R} \$ 2.392,00$ (Tier 3). Assim, o uso de EDI trouxe benefícios relevantes, superando os gastos com a adoção e o uso do mesmo.

As concessionárias que fazem a atividade de distribuição da montadora pesquisada possuem conexão via rede da corporação e semanalmente, no mesmo dia e horário, emitem o conhecimento da demanda de cada região atendida pela concessionária, permitindo que a montadora atualize sua previsão mensal, semestral e anual. Os pedidos de carros para atender às vendas realizadas também são enviados por este meio, assim como as informações sobre financiamento aos compradores. Há interligação eletrônica das operações de venda, de financiamento e de produção. Outra informação enviada por este meio é a necessidade de peças de reposição da concessionária. $\mathrm{O}$ elo montadora e distribuição/vendas é caracterizado por forte integração e comprometimento dos proprietários das concessionárias de seguirem os procedimentos definidos pela montadora. Outro canal disponível pela rede da empresa, via Internet, dá acesso à compra direta, em

QUADRo 2 : Características gerais da empresa e das atividades logísticas.

\begin{tabular}{|c|c|c|}
\hline & EMPRESASAUTOMOBILÍSTICAS & EMPRESAS DE ALIMENTOS \\
\hline Custo do produto & Alto & Baixo \\
\hline $\begin{array}{l}\text { Custo relativo dos } \\
\text { componentes no valor do } \\
\text { produto }\end{array}$ & Alto & Baixo \\
\hline Grau de integração & $\begin{array}{l}\text { Coordenação no fornecimento e } \\
\text { concessão da distribuição } \\
\text { (direto] }\end{array}$ & $\begin{array}{l}\text { Fraco no fornecimento (acordos } \\
\text { comerciais] e na distribuição para } \\
\text { varejo (intermediação comercial), } \\
\text { contratos com distribuidores e brokers }\end{array}$ \\
\hline $\begin{array}{l}\text { Importância maior } \\
\text { da logística }\end{array}$ & no fornecimento & na distribuição \\
\hline $\begin{array}{l}\text { Política de Estoque } \\
\text { componentes }\end{array}$ & $\begin{array}{c}\text { Justi-in-time e Kanban e } \\
\text { consignação }\end{array}$ & Reposição periódica \\
\hline $\begin{array}{l}\text { Política de Estoque produto } \\
\text { acabado }\end{array}$ & Produção Contra Pedido (MTO) & Produção para Estoque (MTS) \\
\hline
\end{tabular}


que o interessado monta o produto desejado, escolhendo o modelo e acessórios, definindo as condições de pagamento e entrega.

Esta forma de coordenação da demanda nacional, consolidação de informações para atualização da previsão, constitui a incorporação do conhecimento de cada localidade para ajuste em prazo mais curto das necessidades de produção. Isto representa diminuição do horizonte de planejamento e programação da produção empurrada, aproximando o ponto de desacoplamento para os locais de decisão para programação da produção para atendimento à demanda. mite a postergação logística, pela qual a rede supermercadista diminui o tempo de ciclo de compras para atender suas necessidades em prazos mais curtos, tendo fornecimentos mais freqüentes. A garantia da disponibilidade dos produtos nas prateleiras e redução, senão eliminação, dos estoques de bastidores de suas lojas é possível pelo encurtamento do horizonte de planejamento para atender às suas necessidades, com giro mais rápido de seus estoques. Há também, nesta estrutura de centralização de pedidos nos CDs e, a partir deles, distribuição dos produtos às lojas, ganhos de escala nos custos de transporte, desde o fornecimento dos processadores de alimentos até o CD e do CD para as lojas com arranjo dos pedidos para entrega já customizados a cada ponto de distribuição, inclusive etiquetados, com preço do local do serviço.

Porém, a Internet abrange um número maior de parceiros comerciais a jusante com pequeno varejo regional, por meio de seus representantes comerciais e/ou distribuidores de seus produtos. Estas tecnologias são usadas nas atividades de compra/suprimentos e, principalmente

A estrutura da cadeia automobilística, onde há sistemistas e subsistemistas em seu canal de fornecimento, é outra forma de consolidação, no caso na montagem de sistemas, que facilita a coordenação entre estoque empurrado e puxado, agilizando o giro de estoques no fluxo físico da cadeia como um todo. A coordenação deste fluxo físico só é possível pela agilidade na troca de informações por meio eletrônico e compartilhamento no planejamento e na programação de operações para gestão da demanda. Há centralização de estoques/operações de montagem que também representa consolidação de transporte/carga no envio destes sistemas. Isto é possível, dadas as características do produto (modular) e de seus processos de fabricação (intermitentes), que permitem flexibilidade no processo de manufatura, viabilizado pelo acesso à informação em tempo real, com benefícios de economia de escala no transporte.

\section{Troca eletrônica de informações em empresas da indústria de alimentos}

$\mathrm{O}$ uso do EDI atinge um pequeno número de parceiros das empresas alimentícias pesquisadas, sendo geralmente para troca de informações com grandes varejistas, que são os indutores principais na adoção de troca eletrônica de informações. Nesta situação, as grandes redes supermercadistas reestruturaram a organização de suprimento de suas lojas, adotando centrais de distribuição (CD) em que as necessidades de reposição dos produtos nas gôndolas são centralizadas, assim como a distribuição dos mesmos para reabastecimento. Esta organização per- venda/marketing.

O uso da Internet nas transações de venda direta com alguns dos seus clientes foi observado em três das empresas pesquisadas e na usina. A maioria das vendas realizadas por vendedores e representantes comerciais (venda indireta) utiliza a Internet para o envio de pedidos dos clientes a uma central de pedidos. Para acesso destes vendedores à central de pedidos da empresa pela Internet laptops. Observa-se neste caso a consolidação de pedidos na central de pedidos, o que representa um recurso importante para o planejamento da logística de distribuição. A rede supermercadista se vale neste percurso (CD e lojas) de economias de transporte pelo uso comum do veículo para entrega em diferentes pontos de sua rede de distribuição.

O processo de compras de materiais em uma das empresas processadoras de alimentos e na usina é realizado principalmente por mecanismos como leilão via Internet. Este meio é usado apenas para algumas categorias de itens de compra. O uso de troca eletrônica de informações para compras para ressuprimento de materiais é menor do que nas vendas. Um dos motivos pode ser a falta de capacitação de fornecedores da indústria de alimentos para uso das TIs e também porque é o varejo quem induz o uso de troca eletrônica de informações.

Em todas as empresas foi notado que as áreas de compra e venda foram as mais afetadas, embora as demais também tenham sofrido impactos da troca eletrônica de informações. Na área de logística foi observada são usados o computador dos clientes ou palmtops, ou 
maior facilidade para conhecimento e visualização de estoque, para gestão de transportes e planejamento da entrega dos produtos. Uma atividade bastante afetada foi a do processamento de pedidos e envio de ordens de compra aos fornecedores, que se tornou mais ágil. Embora as empresas tenham declarado que podem ter melhor conhecimento sobre os níveis de estoques, ainda não verificaram reduções nos mesmos. Enquanto algumas empresas responsabilizam este fato pela implantação recente da troca eletrônica, há que lembrar que estas empresas têm política de estoques de reposição periódica de seus componentes e produção para estoque (make to stock - MTS) de produto acabado.

As empresas produtoras de alimentos também tiveram redução no tempo de ciclo de pedidos, como consequiência da redução de tempo no processamento de pedidos com parceiros a jusante. Uma das empresas também declarou que reduziu $40 \%$ do tempo de ciclo de compras. Além destes impactos, a maioria das empresas destaca a redução de erros e documentação de processo como principais benefícios proporcionados pela troca de informação por meios eletrônicos.

Três das quatro empresas pesquisadas, produtoras de alimentos, compram açúcar cristal, líquido e invertido, sendo que em uma delas (segmento de confeitos) o fornecimento de açúcar líquido é via contrato, diferenciada das demais também porque o pedido de compra de açúcar líquido é via EDI. O açúcar líquido tem o shelf life de 15 dias e a necessidade de remessa é gerada automaticamente, assim como o envio do pedido para reabastecimento. Há um sistema de controle no tanque de armazenagem de açúcar líquido, por instrumentação, que sinaliza a necessidade. Este sinal é captado automaticamente pelo ERP (Enterprise Resource Planning), que emite via EDI, para o fornecedor, a autorização para remessa. Assim, podese dizer que este elo de fornecimento de açúcar líquido tem gestão compartilhada no estoque e processamento de pedidos com o fornecedor para atender às necessidades desta empresa (SOUZA, 2005).

\section{Comparação entre os casos}

Analisando o uso de TIs para troca eletrônica de informações nos setores automobilístico e de alimentos, pode-se verificar que o primeiro já se encontra bem mais capacitado e organizado que o segundo para o uso de TIs como o EDI e a Internet, obtendo, assim, maiores benefícios com o uso das mesmas.

Um dos motivos para essa diferença se deve ao tempo de uso de TIs para troca eletrônica de informação. Enquanto a troca eletrônica de informações com os parceiros co- merciais nas empresas da indústria de alimentos é recente, adotada pelas empresas pesquisadas por volta dos anos 2000 e 2001, esta prática já existe nas empresas do ramo automobilístico desde a década de 1980. Na empresa fornecedora de espelhos retrovisores (Tier 1), por exemplo, a troca eletrônica de dados vem ocorrendo desde 1988.

O Quadro 3 apresenta uma síntese sobre as principais características da troca eletrônica de informações nas empresas pesquisadas no setor automobilístico e de alimentos.

O número de parceiros comerciais que se comunicam de forma eletrônica é bem maior na cadeia automobilística, uma vez que as montadoras fazem esta exigência aos seus fornecedores e concessionárias. A troca de informações eletrônica a montante viabiliza o recebimento Justin-Time, facilita o kanban e o controle de estoques em consignação de materiais importados. Os fornecedores, por sua vez, podem também operar conforme pedido, diminuindo desordens na sua programação. A relação da montadora com as concessionárias é estruturada para controle da demanda e operações de vendas e financiamento. $\mathrm{O}$ setor automobilístico apresenta também padrão de comunicação (RND - Rede Nacional de Dados e EDIFACT - sigla em inglês para Intercâmbio Eletrônico de Dados para Administração, Comércio e Transportes), estabelecido entre parceiros deste setor, o que não está disseminado na indústria alimentícia.

\section{utro fator importante, decorrente da força das montadoras na cadeia automobilística, é o padrão estabelecido para troca eletrônica de informações.}

\footnotetext{
A falta de um padrão de comunicação estabelecido entre as empresas alimentícias e seus vários parceiros é um dos grandes problemas verificados atualmente neste setor. Estas se comunicam de diferentes formas com seus parceiros. Com grandes redes supermercadistas, por exemplo, usam o EDI, enquanto que com seus distribuidores e brokers, representantes comerciais e vendedores usam Internet, fax ou telefone. Algumas informações são transmitidas diretamente pelos parceiros e outras, enviadas por vendedores, representantes comerciais ou distribuidores, que são os intermediários da empresa e negociam com varejistas regionais e pequenos. A diversidade nos procedimentos de vendas nas processadoras de alimentos gera custos desnecessários e problemas na padronização e processamento das informações.
} 
É importante também destacar que o tipo e custo relacionados ao produto são fatores que devem ser considerados. O custo envolvido na fabricação de um veículo automotor é bem maior relativamente que na fabricação de produtos alimentícios. Assim, o fluxo físico da cadeia automobilística é responsável por produtos de maior valor agregado que os movimentados na cadeia de alimentos. Isto faz com que no setor automobilístico haja maior pressão para coordenação e troca de informações rápidas e precisas que no setor alimentício.

Também as políticas de produção adotadas pelas empresas são fatores que exigem o uso da troca eletrônica de informações na cadeia automobilística, que produz contra pedido. Informações precisas e em tempo real são essenciais para compartilhamento no planejamento das necessidades e programação para atendimento dos pedidos, o que resulta necessariamente na redução dos níveis de estoque.

Já as empresas pesquisadas no setor de alimentos produzem para estoque (MTS). Embora tenha sido observada iniciativa para compartilhamento de informações sobre as necessidades de materiais com o fornecedor, esta ocorrência ainda é incipiente. Dessa forma, o uso da troca eletrônica de informações ainda não tem trazido grandes alterações na gestão e reduções dos níveis de estoque na indústria de alimentos. Se a análise abarcasse o varejo, os resultados seriam mais significativos, dado que, desde o início da década de 1990, este segmento reorganizou o suprimento de suas lojas, com centralização de estoques em centros de distribuição, e induziu seus fornecedores para adoção do EDI.

\section{CONSIDERACÕES FINAIS}

Os resultados apresentados indicam a importância do uso de EDI (tradicional e via Web) e da Internet na gestão de estoques, no transporte e no processamento de pedidos. Observou-se que o uso destas tecnologias é disseminado na cadeia automobilística, tanto a montante quanto a jusante, e mais intensa nas vendas do que em compras nas empresas da indústria de alimentos.

Quadro 3: Comparação do uso da troca eletrônica de informações nas empresas da indústria automobilística e de alimentos.

\begin{tabular}{|c|c|c|}
\hline & EMPRESAS AUTOMOBILÍSTICAS & EMPRESAS DE ALIMENTOS \\
\hline Implantação & Desde 1988 (empresa Tier 1) & Entre 2000 e 2001 \\
\hline Motivo & Pressão dos clientes (montadoras] & $\begin{array}{c}\text { Pressão principalmente do grande varejo e } \\
\text { benefícios das Tls }\end{array}$ \\
\hline Parceiros na troca eletrônica & $\begin{array}{l}\text { Maioria dos clientes } \\
\text { [concessionárias] e fornecedores }\end{array}$ & $\begin{array}{l}\text { Poucos fornecedores e } \\
\text { mais significativa com clientes }\end{array}$ \\
\hline Atividades mais afetadas & Compras, Vendas e Logística & $\begin{array}{l}\text { Moderada em Compras, mais significativa } \\
\text { em Vendas e Logística de distribuição }\end{array}$ \\
\hline \multicolumn{3}{|c|}{ Estratégias na cadeia } \\
\hline Consolidação & $\begin{array}{l}\text { - Montagem de sistemas } \\
\text { - Conhecimento da demanda } \\
\text { - Logística de fornecimento }\end{array}$ & $\begin{array}{c}\text { - Pedidos para atender distribuição ao varejo } \\
\text { - Centralização dos estoques } \\
\text { - Logística de distribuição }\end{array}$ \\
\hline Postergação & $\begin{array}{l}\text { Adianta-se o ponto em que o } \\
\text { estoque é puxado pela consolidação } \\
\text { de conhecimento local }\end{array}$ & $\begin{array}{l}\text { Adianta-se o conhecimento da } \\
\text { demanda, pela consolidação } \\
\text { dos pedidos nos CDs }\end{array}$ \\
\hline \multicolumn{3}{|c|}{ Impactos na logística das empresas processadoras } \\
\hline Processamento de pedidos & $\begin{array}{l}\text { - Redução significativa no tempo e } \\
\text { custo de processamento de pedido }\end{array}$ & $\begin{array}{c}\text { - Redução de erros e redução moderada no } \\
\text { tempo de processamento de pedido }\end{array}$ \\
\hline Manutenção de estoques & $\begin{array}{l}\text { - Redução nos níveis e giro de estoque } \\
\text { - Redução de custos de estoque }\end{array}$ & $\begin{array}{l}\text { - Melhor conhecimento dos níveis de } \\
\text { estoques }\end{array}$ \\
\hline Transporte & $\begin{array}{l}\text { - Redução de fretes adicionais } \\
\text { - Redução de custos de transporte }\end{array}$ & $\begin{array}{c}\text { - Melhor planejamento de transporte e } \\
\text { entregas }\end{array}$ \\
\hline
\end{tabular}


A adoção da troca eletrônica de informações nas empresas da indústria automobilística foi determinada pela montadora que coordena o fornecimento de sistemas, subsistemas, peças e materiais, de acordo com as necessidades explicitadas, assim como impõe às suas concessionárias os procedimentos para controle das vendas, tendo, assim, maior visibilidade para gestão da demanda. Outro fator importante, decorrente da força das montadoras na cadeia automobilística, é o padrão estabelecido para troca eletrônica de informações.

Já para as empresas produtoras de alimentos, a disseminação no uso destas tecnologias não é tão significativa, sendo que, quando usadas efetivamente, há condições para agilizar o recebimento de componentes de suas formulações e propiciar maior controle de estoques, como é o caso do fornecimento de açúcar líquido. O uso da Internet é mais comum na relação destas empresas com agentes dos canais de distribuição que fazem a intermediação com o varejo, enquanto que a troca eletrônica de informações via EDI, rede proprietária, se dá na relação de venda direta com as grandes redes supermercadistas.

Assim, conclui-se que as empresas dos dois setores adotam o uso de EDI e Internet pressionadas por outros parceiros, sendo que os fornecedores de componentes para veículos automotores o fazem induzidos pelas montadoras, e as empresas do setor alimentício seguem padrão determinado pelo varejo. Estas últimas são motivadas também por vislumbrar os benefícios do uso destas tecnologias para integração de processos das áreas de suprimentos/compras, produção, vendas e logística de distribuição. A montadora é beneficiada principalmente pela integração entre vendas de veículos e peças de reposição e compras de componentes e na logística de suprimento.

A distinção das características dos setores industriais analisados diferencia a intensidade na adoção de tecnologias para troca eletrônica de informação, bem como seus impactos. Dentre as principais características diferenciadoras destacam-se: custo e complexidade de produção, perecibilidade dos produtos, políticas de estoque, presença de contratos na relação entre parceiros comerciais.

$\mathrm{O}$ alto custo dos materiais e produtos, maior complexidade, política de entrega de componentes just-in-time e just-in-sequence e produção contra pedido - presentes nas empresas da indústria automobilística - aumenta a pressão e os investimentos na adoção do EDI e da Internet entre montadora, fornecedores, operadores logísticos e concessionárias. Entre eles há relações contratuais. Por outro lado, o baixo custo associado aos produtos alimentícios, sua característica de giro rápido (bens de consumo não-duráveis) e políticas de fabricação para estoque, embora justificassem a necessidade de sincronizar fluxo físico e de informação na distribuição de seus produtos (para ter-se maior controle no atendimento à demanda), não implicaram na adoção intensiva das TIs nas empresas da indústria de alimentos, como observado na automobilística. Ainda não se consolidou a prática de relações contratuais entre as processadoras de alimentos e seus parceiros comerciais (fornecedores, principalmente).

Devido a isso, os impactos na indústria de alimentos são menores, observados principalmente na gestão de transportes e no processamento de pedidos para distribuição. Já na cadeia automobilística o maior impacto é na gestão de estoques de peças e componentes, propiciado pelo uso intensivo de EDI no processamento de pedidos, que são repassados aos fornecedores e compartilhados com operadores logísticos que fazem o arranjo da carga e o transporte direto na linha de produção (just-in-sequence). Há também maior compartilhamento de informação estratégica entre montadora e concessionárias.

As empresas alimentícias se preocupam mais com a redução de custos de transporte na distribuição física, devido ao valor relativo desta atividade no custo de seus produtos. Já o valor agregado dos materiais e produtos na cadeia automobilística e a capacitação organizacional adquirida pela reestruturação produtiva pela qual passou na última década fazem com que o foco seja no controle de estoques em todo o percurso, desde os fornecedores até as concessionárias.

Assim, enquanto as empresas processadoras de alimentos percebem redução de erros e tempo de processamento de pedido para distribuição, maior visibilidade dos estoques e melhoria em sua atividade de planejamento de transporte em suas entregas para o varejo, as empresas da indústria automobilística já têm resultados de diminuição significativa no tempo e custo de processamento de pedido, nos níveis e custo de estoque e de fretes adicionais (necessidades urgentes) e no custo de transporte nos canais de fornecimento. A diferença na percepção do desempenho do uso destas tecnologias, qual seja, as empresas de alimentos ainda esperam obter benefícios, enquanto que as automobilísticas já usufruem de resultados, pode ser devida a que estas últimas têm relações de parceria mais consolidadas que as primeiras, o que favorece o projeto de adoção de tecnologias compartilhadas, além de facilitar a troca de informações. Afora estes aspectos, há que lembrar também que a cadeia automobilística adota há mais tempo estas tecnologias.

Pode-se deduzir que a disseminação da troca eletrônica de informações depende do poder de barganha da empresa frente a seus parceiros a montante e a jusante. 
Seu uso permite maior controle das operações e facilita a coordenação do atendimento à demanda com a programação das necessidades para tal, permitindo agilizar o processamento de pedidos entre as empresas, reduzindo níveis de estoques e custos associados a operações de transporte e manutenção de estoques. Vale ainda lembrar que o custo de adoção e de uso das tecnologias que viabilizam a troca eletrônica de informações, mesmo que seja por rede proprietária, é compensado pelos ganhos decorrentes.

Foi possível observar também que o EDI tradicional é utilizado principalmente entre parceiros cuja transação é regulada por contratos ou por relacionamentos mais estreitos, seja para suprimento como na distribuição. Por outro lado, a Internet é utilizada principalmente nos pedidos de compra e venda de commodities, onde na maioria das vezes não existem contratos formais, somente acordos verbais estabelecidos no momento da compra e venda. Isto explica também os maiores benefícios obtidos pela troca eletrônica de informações na indústria automobilística, que tem contratos formais estabelecidos com a maior parte de seus parceiros, enquanto na indústria de alimentos esta prática ainda não é a regra. Nos casos analisados, foi observado apenas no fornecimento de açúcar líquido, em que há contrato anual e os pedidos de remessa são via EDI, quando disparado pelo ERP após ser detectado por sensor instalado no tanque de armazenagem.

Destaca-se assim: enquanto na indústria de alimentos as informações trocadas eletronicamente são usadas para controle das operações na distribuição física (com trans- portadoras para monitorar as entregas, com o varejo para envio de pedidos de compra e controle de pagamento), nas empresas da indústria automobilística são trocadas também informações mais sensíveis. Há compartilhamento de programas de produção com transportadoras, fornecedores e montadora para realização de just-insequence e gestão de estoques. Entre fornecedores e montadora, há também trabalho conjunto no processo de desenvolvimento de produto. Na cadeia automobilística, a jusante, a montadora controla semanalmente, com suas concessionárias, a expectativa de vendas, havendo desta forma previsão conjunta da demanda e controle centralizado de estoque (de peças para reposição).

Conclui-se que a agilidade na troca eletrônica de informações contribui para que o sistema logístico seja um recurso competitivo da empresa, permitindo consolidação de carga (custo) e postergação na logística (responsividade). Porém, esta capacitação da logística só é possível com a reestruturação da rede logística e do sistema produtivo, permitindo centralização de pedidos, de estoques e de montagem dos pedidos para atender às necessidades colocadas pela explicitação da demanda. O ponto de desacoplamento na cadeia automobilística é situado mais a montante na fabricação, com a atualização de dados sobre a demanda, com conhecimento dos diferentes locais de venda (concessionárias). Isto permite a reprogramação do mix de produtos. Na cadeia de alimentos o ponto de desacoplamento é próximo ao mercado, nos CDs (Centros de Distribuição) de grandes redes varejistas.

\section{Artigo recebido em 15/06/2005 Aprovado para publicação em 05/12/2005}

\section{- Referências Bibliográficas}

A MELHOR de cada segmento. Revista As Melhores do Transporte, ano 14, n.14, nov. 2001.

ANTONIO, D.G. Distribuição - DRP (Distribution Requirements Planning) no âmbito da gestão da demanda. 2003. 58 p. Monografia (Graduação em Engenharia de Produção) - Departamento de Engenharia de Produção, Universidade Federal de São Carlos, São Carlos.
BALLOU, R.H. Gerenciamento da cadeia de suprimentos: planejamento, organização e logística empresarial. Porto Alegre: Bookman, 2001.

BOWERSOX, D.J.; ClOSS, D. J. Logística empresarial: o processo de integração da cadeia de suprimento. São Paulo: Atlas, 2001.

CHOPRA, S.; MEINDL, P. Gerenciamento da cadeia de suprimentos. São Paulo: Prentice Hall, 2003.
COUNCIL OF SUPPLY CHAIN MANAGEMENT PROFESSIONALS (CSCMP). Definition of logistics management. Disponível em: <http:/ /cscmp.org/Website/AboutCSCMP/ Definitions/Definitions.asp $>$. Acesso em: jan. 2005

EAN Brasil. Introdução ao EDI. Biblioteca Técnica, 2003. Disponível em: $<$ www.eanbrasil.org.br/html/ contentManagement/files/Biblioteca/ guia_implanta_edi.pdf > Acesso em: dez., 2003.

FERREIRA, K. A. Tecnologia da informacão e logística: os impactos do EDI nas operações logísticas de uma empresa da indústria automobilística. 2003. 147 p. Monografia (Graduação em Engenharia de Produção) - Departamento de Engenharia de Produção / Escola de Minas, Universidade Federal de Ouro Preto, Ouro Preto. 


\section{- Referências Bibliográficas}

FERREIRA, K.A.; SOUZA, L.S.; ASSUMPČ̃̃O, M.R. O uso da Tecnologia de Informação na Indústria de Alimentos. In: Simpósio de Gestão de Inovação Tecnológica, XXIII, 2004, Curitiba. Anais... Curitiba, PR out. 2004, CD-ROM.

GALLINA, R. As cadeias produtivas de transformação de plásticos na indústria automobilística: um estudo multicaso na utilização do EDI ao longo de uma cadeia de pequenas e médias empresas nacionais. 2001. 149 p. Dissertação (Mestrado em Engenharia de Produção). Departamento de Engenharia de Produção, Escola Politécnica da Universidade de São Paulo, São Paulo, 2001.

GIANNOCCARO, I.; PONTRANDOLFO, $P$. Aligning inventory managements systems to supply chain types. In: DIERDONCK, R; VEREECKE,A. (Eds). Operations management - crossing borders and boundaries: the changing role of operations. Ghent, Belgium: Academic Press A Cientific Booksellers, 2000.
HAGELAAR, G.; VAN DER VORST, J.G. Environmental Supply Chain Management: using life cycle assessment to structure supply chains. International Food and Agribusiness Management Review, v. 4 p. 399-412, 2002.

HASSELBRING, W.; WEIGAND, H Languages for electronic business communication: state of the art. Industrial Management \& Data Systems, v.101, n. 5, p. 217-226, 2001.

HOEK, R.; VOS, B.; COMMANDEUR, H. Restructuring European Supply Chains by Implementing Postponement Strategies. Long Range Planning, v. 32, n. 5, p. 505-518, 1999

LAMBERT, D.M; STOCK, J.R.; VANTINE,J.G. Administração estratégica da logística. São Paulo: Vantine Consultoria, 1998.

LANCIONI, R.; SMITH, M. F.; SHAU, H. J. Strategic Internet application trends in supply chain management. Industrial Marketing Management, $\mathrm{n}$. 32, p. 221-217, 2003.
LANKFORD, W.M.; JOHNSON, J.E. EDI via the Internet. Information Management \& Computer Security, v. 8, n. 1, p. $27-30,2000$.

LAUDON, K.C.; LAUDON, J.P. Sistemas de informação com internet. 4. ed. Rio de Janeiro: LTC, 1999.

MACHUCA, J.A.; BARAJAS, R.P. The impact of electronic data interchange on reducing bullwhip effect and supply chain inventory costs. Transportation Research Part E: Logistics and Transportation Review, p. 1-20, 2003. Disponível em: < www.elsevier.com/locate/tre > . Acesso em: dez. 2003.

NAZÁRIO, P. Papel do Transporte na Estratégia Logística. In: FLEURY, P.F.; FIGUEIREDO, K.; WANKE, P. (Org.). Logística empresarial. São Paulo: Atlas, 2000. p. 126-132. Coleção COPPEAD de Administração.

PIRES, S.R.I. Gestão da cadeia de suprimentos: conceitos, estratégias, práticas e casos - supply chain management. São Paulo: Atlas, 2004
SLACK, N. et al. Administração da produção. 2. ed. São Paulo, 2002.

SOUZA, L. O uso do ERP (Enterprise Resource Planning) e seu impacto na gestão de suprimentos em empresas da indústria de alimentos. 2005. 161 p. Dissertação (Mestrado em Engenharia de Produção). Departamento de Engenharia de Produção, Universidade Federal de São Carlos, São Carlos.

STANK, T.; CRUM, M.; ARANGO, M Benefits of Interfirm Coordination In Food Industry Supply Chains. Journal of Business Logistics, v. 20 n. 2, p. 21-41, 1999.

WANKE, P. Gestão de estoques. In: FLEURY, P.F.; FIGUEIREDO, K. WANKE, P. (Org.). Logística empresarial. São Paulo: Atlas, 2000. p. 177-208. Coleção COPPEAD de Administração.

\section{Sobre os autores}

\section{Karine Araújo Ferreira}

Doutoranda em Engenharia de Produção / UFSCar

Universidade Federal de São Carlos

Endereço: Rod. Washington Luís, km 235 - CEP: 13565-905 - São Carlos / SP

Telefone: (16) 3351-8236 (ramal: 240 ou 257)

E-mail: karine@dep.ufscar.br

\section{Maria Rita Pontes Assumpção Alves}

Profa. Dra. no Departamento de Engenharia de Produção / UFSCar

Universidade Federal de São Carlos

Endereço: Rod. Washington Luís, km 235 - CEP: 13565-905 - São Carlos / SP

Telefone: (16) 3351-8236 (ramal: 240 ou 257)

E-mail: rita@dep.ufscar.br 